\title{
Article \\ Route Planning of Helicopters Spraying Operations in Multiple Forest Areas
}

\author{
Shuping Fang ${ }^{1,2}$, Yu Ru ${ }^{1, *}$, Yangyang Liu ${ }^{3, *}$, Chenming $\mathrm{Hu}{ }^{1}$, Xuyang Chen ${ }^{1}$ and Bin Liu ${ }^{1}$ \\ 1 College of Mechanical and Electronic Engineering, Nanjing Forestry University, Nanjing 210037, China; \\ fangsp@njfu.edu.cn (S.F.); Hucm211@njfu.edu.cn (C.H.); cxy1104@njfu.edu.cn (X.C.); \\ liubin96@njfu.edu.cn (B.L.) \\ 2 College of Mechanical Engineering, Anhui Science and Technology University, Chuzhou 233100, China \\ 3 School of Engineering, Anhui Agricultural University, Hefei 230036, China \\ * Correspondence: superchry@njfu.edu.cn (Y.R.); gwglyy@ahau.edu.cn (Y.L.); Tel.: +86-139-5177-8251 (Y.R.); \\ +86-139-5100-8208 (Y.L.)
}

check for updates

Citation: Fang, S.; Ru, Y.; Liu, Y.; Hu, C.; Chen, X.; Liu, B. Route Planning of Helicopters Spraying Operations in Multiple Forest Areas. Forests 2021, 12, 1658. https://doi.org/10.3390/ f12121658

Academic Editor:

Krzysztof Stereńczak

Received: 4 November 2021

Accepted: 26 November 2021

Published: 29 November 2021

Publisher's Note: MDPI stays neutral with regard to jurisdictional claims in published maps and institutional affiliations.

Copyright: (c) 2021 by the authors. Licensee MDPI, Basel, Switzerland. This article is an open access article distributed under the terms and conditions of the Creative Commons Attribution (CC BY) license (https:// creativecommons.org/licenses/by/ $4.0 /)$.
Abstract: It is of great value to research the problem of forest pest and disease control. Currently, helicopters play an important role in dealing with this problem. However, the spraying route planning still depends on the pilot's driving experience, which leads to low efficiency and less accurate coverage. For this reason, this paper attempts to use intelligent algorithms to plan the pesticide spraying route for helicopters. When the helicopter is conducting spraying operations in multiple forest areas, the routes are divided into two parts: pesticide spraying routes for individual forest areas and dispatch routes between multiple forest areas. First, the shorter spraying route with fewer turnarounds for individual forest areas was determined. Then a two-layer intelligent algorithm, a combination of a genetic algorithm (GA) and ant colony optimization algorithm (ACO), was designed to determine the dispatch route between multiple forest areas, which is referred to as GAACO-GA. The performance was evaluated in self-created multiple forest areas and compared with other two-layer intelligent algorithms. The results show that the GAACO-GA algorithm found the shortest dispatch route (5032.75 m), which was 5.60\%, 5.45\%, 6.54\%, and $4.07 \%$ shorter than that of GA-GA algorithm, simulated annealing-GA (SA-GA) algorithm, ACO-GA algorithm, and particle swarm optimization-GA (PSO-GA) algorithm, respectively. A spraying experiment with a helicopter was conducted near Pigzui Mountain, Huai'an City, Jiangsu Province, China. It was found that the flight path obtained from the proposed algorithm was $5.43 \%$ shorter than that derived from a manual planning method. The dispatch route length was reduced by $16.93 \%$, the number of turnarounds was reduced by 11 times, and the redundant coverage was reduced by $17.87 \%$. Moreover, helicopter fuel consumption and pesticide consumption decreased by $10.56 \%$ and $5.43 \%$, respectively. The proposed algorithm can shorten the application route, reduce the number of turnarounds and the cost of spraying operations, and has the potential for use in spraying operations in smart forestry and agriculture.

Keywords: route planning; helicopter; two-layer intelligent algorithm; genetic algorithm; ant colony optimization algorithm; multiple forest areas; spraying operations

\section{Introduction}

Carbon neutrality has become a hot topic and it is of concern to the Chinese government and people. Forests play an important role in achieving carbon neutrality [1]. At present, China has 220 million hectares of forests, with $23.04 \%$ forest cover and 79,542,800 hectares of planted forests [2]. The carbon sink of China's forests is equivalent to neutralizing $21.55 \%$ of the national industrial carbon emissions from 1978 to 2018 . Forest plantations hold an important share of the Chinese forests [2]. However, in recent years, pests and diseases have accounted for $23.7 \%$ in forest plantations, and the economic loss due to pests and diseases was more than 110 billion RMB [3]. Not only in China, but also in other 
parts of the world, forest pests and diseases often occur and have caused serious economic losses [4-6]. Thus, pest and disease control is an important and indispensable part of food and forest production [7-10].

Aerial spraying is essential to modern forestry and plays an increasingly important role in pest and disease control and in other applications [11,12]. Route planning is crucial for aerial applications in forestry to reduce the amount of applied pesticide and aviation fuel consumption and to improve the accuracy of the aircraft when following the track $[13,14]$.

Current research on route planning for aerial applications has mainly focused on unmanned aerial vehicles (UAVs) [15]. Zhan et al. [16] developed an intelligent delivery system for biological control agents using electric multi-rotor UAVs and achieved $36.75 \%$ coverage redundancy. Cabreira et al. [17] reviewed studies of UAV-based coverage path planning for differently shaped areas (e.g., rectangles, concave polygons, and convex polygons). Causa et al. [18] proposed a multi-UAV path planning algorithm in heterogeneous Global Navigation Satellite System (GNSS) coverage scenarios. Xu et al. [19] optimized the operation sequence and dispatch routes for multiple areas using a genetic algorithm (GA) and achieved full-coverage route planning of a forest spraying UAV. Fan et al. [20] performed path planning optimization of UAVs in mountainous operating conditions and minimized energy consumption using a simulated annealing (SA) algorithm. Wang et al. [21] conducted path planning of a forest spraying UAV and ranked the 3D operation orders based on an improved ant colony optimization (ACO) algorithm to generate transfer paths with a shorter total length. Although these studies provide references for helicopter path planning, there are differences between helicopters and UAVs. UAVs, in particular, rotary-wing UAVs can perform flexible turnaround operations. Therefore, path planning for UAVs typically aims for the shortest path and does not consider the number of turnarounds. As a result, a UAV enter a forest area more than once. Those routes are not suitable for a manually driven helicopter. Sometimes there are often many shorter routes for a UAV, which are also difficult for helicopters to follow.

Helicopters are commonly used for airborne operations in agriculture and forestry in the world [22,23]. However, few studies focused on route planning for helicopters. Helicopters have several advantages over UAVs [22,23], such as higher pesticide carrying capacity, higher operational efficiency, and longer endurance, making them more suitable for application operations in complex terrains, such as hills, mountains, and large forested areas. However, the spraying route planning still depend on the pilot's driving experience, which leads to low efficiency and less accurate coverage [23].

The goal of this paper is to develop a route planning method that provides the shorter routes with fewer turnarounds when the helicopter spray pesticide in multiple forest areas. First, the suitable route was determined for a single area; then the multiple lowslope forest area operation was simplified into one plane operation, and an intelligent two-layer algorithm that combines a GA and ACO algorithm (GAACO-GA) was designed to determine the optimum dispatch route. Finally, the proposed algorithm was verified by experiments.

\section{Materials and Methods}

When the helicopter is conducting spraying operations in multiple forest areas, the routes are divided into two parts: spraying routes for individual forest areas and dispatch routes between multiple forest areas.

\subsection{Spraying Route Planning Algorithm for a Single Forest Area}

With the development of variable application techniques, the spray volume can be regulated according to the operating altitude and flight speed, ensuring consistent pesticide applications in the canopy of multiple forest areas [24,25]. By using this technique, multiple low-slope forest area applications were simplified into one plane application. To ensure full coverage when spraying $[26,27]$, the spraying route needs to extend beyond the boundary of the operation area. Therefore, spraying outside of the designated areas is minimized, and 
the spraying range is more precise if the length of the spray routes outside the boundary is reduced. At a given spray width, when the number of turnarounds is fewer, it means that the individual routes are longer. Such routes are more suitable for helicopters. How to determine that suitable spraying route of a single forest area is given below.

(1) Establishing a coordinate system for the operating area. We assume that the operation area is a polygon with $\mathrm{n}$ sides and is located in the eastern longitude and northern latitude region. The polygon operation area is located in the first quadrant of the coordinate system to facilitate the analysis. Further, the smallest latitude and longitude values in the operation area are selected as the coordinate origin. The positive direction of the $x$-axis is due east, and the positive direction of the $y$-axis is due north. The coordinate system is shown in Figure 1a.

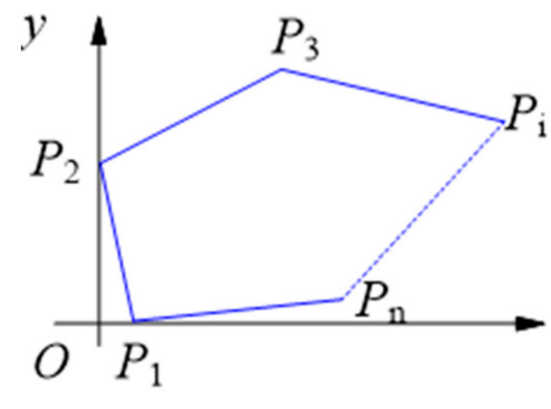

(a)

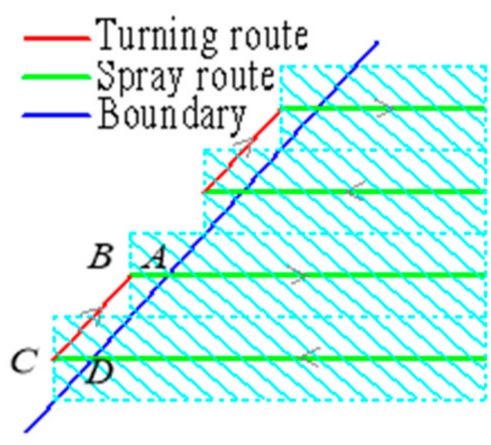

(b)

Figure 1. Spraying area and schematic diagram of the spraying routes at the border. (a) Spray area; (b) The routes at the border.

(2) Calculate the slope of each boundary as follows:

$$
\left\{\begin{array}{c}
k_{j}=\frac{\left|y_{j+1}-y_{j}\right|}{\left|x_{j+1}-x_{j}\right|}, 1 \leq j<n, j \in Z \\
k_{j}=\frac{\left|y_{1}-y_{j}\right|}{\left|x_{1}-x_{j}\right|}, j=n, j \in Z
\end{array}\right.
$$

where $k_{j}$ is the slope of the $j$ th edge, $y_{j}$ is the vertical coordinate of the $j$ th vertex, and $x_{j}$ is the horizontal coordinate of the $j$ th vertex.

(3) Calculate the total length of the spray routes outside the operating area. Most aerial spray applications use parallel flight lines. We use the $x$-axis as the starting edge and calculate the number of routes as follows to achieve full coverage.

$$
\left\{\begin{array}{c}
M_{j}=\frac{\left|y_{j+1}-y_{j}\right|}{W_{s}}, 1 \leq j<n, j \in Z \\
M_{j}=\frac{\left|y_{1}-y_{j}\right|}{W_{s}}, j=n, j \in Z
\end{array}\right.
$$

where $M_{j}$ is the number of application routes required for the $j$ th edge. $W_{s}$ is the spray width.

The total length of the spray routes outside the operating area is computed next. Since the spray routes are parallel, and the spacing is equal to the spray width, the quadrilateral $\mathrm{ABCD}$ shown in Figure $1 \mathrm{~b}$ is a parallelogram. The length $l_{A B}$ can be obtained as follows:

$$
l_{A B}=\frac{W_{s}}{2 k}
$$

where $l_{A B}$ is the length of each spray route outside the operating area, and $k$ is the slope of the operating area boundary line. 
We combine Equations (2) and (3) to obtain the total out-of-area spray distance at each boundary. It is equal to the sum of the lengths of all application routes beyond the regional boundary line.

$$
l_{j}=\frac{M_{j} W_{s}}{2 k_{j}}
$$

where $l_{j}$ is the total length of the out-of-area spray routes at the $j$ th boundary.

Equations (1) and (4) are combined to obtain Equation (5):

$$
\left\{\begin{array}{c}
l_{j}=\frac{\left|x_{j+1}-x_{j}\right|}{2}, 1 \leq j<n, j \in Z \\
l_{j}=\frac{\left|x_{1}-x_{j}\right|}{2}, j=n, j \in Z
\end{array}\right.
$$

The total length of the out-of-area spray routes is equal to the sum of the spray routes outside all the boundaries of the area.

$$
L=\frac{\left|x_{1}-x_{n}\right|}{2}+\sum_{j=2}^{n-1} \frac{\left|x_{j+1}-x_{j}\right|}{2}, j \in Z
$$

where $L$ is the total length of the out-of-area spray routes.

As shown in Equation (6), the shortest total length of the out-of-area spray route is obtained when the spray route is parallel to the $x$-axis, and the $x$-axis of the coordinate system is parallel to the regional boundary line. Thus, the spray route parallel to the boundary of the area is shorter than that not parallel to the boundary.

(4) Determine the coordinate system with fewer number of turnarounds. We use each boundary of the operating area as the $x$-axis and establish the coordinate systems $Z_{1}, Z_{2}$, and $Z_{n}$. Equations (7) and (8) is then used to calculate the number of turnarounds. When the number of turnarounds is minimum, we use that boundary as the $x$-axis.

$$
\begin{gathered}
M=\left\lceil\frac{1}{2} \sum_{j=1}^{n} M_{j}\right\rceil \\
T_{s}=M-1
\end{gathered}
$$

where $M$ is the number of total application routes, $T_{S}$ is the number of turnarounds.

(5) We plan the first spray route offset by $1 / 2$ the spray width parallel to the boundary obtained by step four. Then we plan the spray route one by one, parallel to first spray route offset by the spray width until the area is covered.

To summarize, the shorter out-of-area routes mean more precise route coverage. The acreage of the operating area is approximately equal to the length of the application route multiplied by the spray width. At a given spray width, when the number of turnarounds is lower, it means that the individual routes are longer. Such routes are more suitable for helicopters.

\subsection{Dispatch Route Planning Algorithm for Multiple Forest Areas}

When planting operations are carried out in large forest areas containing fishponds, lakes, animal farms, and military no-fly zones where pesticide applications are not allowed, the forest area is divided into many patches. Once the spraying routes for individual forest areas have been determined, we still need to connect the multiple forest areas, known as the dispatch route. Next, we discuss the algorithm to plan the dispatch route.

For ease of expression, two concepts are defined. Figure 2 shows the spraying operation plan with four sectors. $A_{1}$ and $A_{2}$ are the entry or exit points, respectively, of sector $A$, and $A_{0}$ is the midpoint of line $A_{1} A_{2}$. The same applies to sectors $B, C$, and $D$. The helicopter enters the sector at point $A_{2}$, traverses zone $A$, exits at point $A_{1}$, enters zone $C$ at point $C_{2}$, traverses zone $C$, exits at point $C_{1}$, enters $B_{1}$, traverses zone $B$, exits at $B_{2}$, enters $D_{1}$, traverses zone $D$, exits at $D_{2}$, and returns to point $A_{2}$. The operation order refers to the 
closed loop formed by the line linking the midpoints of the entry and exit points of each zone. $A_{0} C_{0} B_{0} D_{0}$ in Figure 3 is an operation order; it only indicates the operational sequence and not the route traveled by the aircraft. The sum of the lengths of lines $A_{0} C_{0}, C_{0} B_{0}, B_{0} D_{0}$, and $D_{0} A_{0}$ is called operation order length. The dispatch route is an open loop formed by the line linking the entry/exit points of one zone to the entry/exit points of the next zone. The green line segments $A_{1} C_{2}, C_{1} B_{1}, B_{2} D_{1}$, and $D_{2} A_{2}$ form the global dispatch route, as shown in Figure 2. The sum of the lengths of the four-line segments is called the dispatch route length.

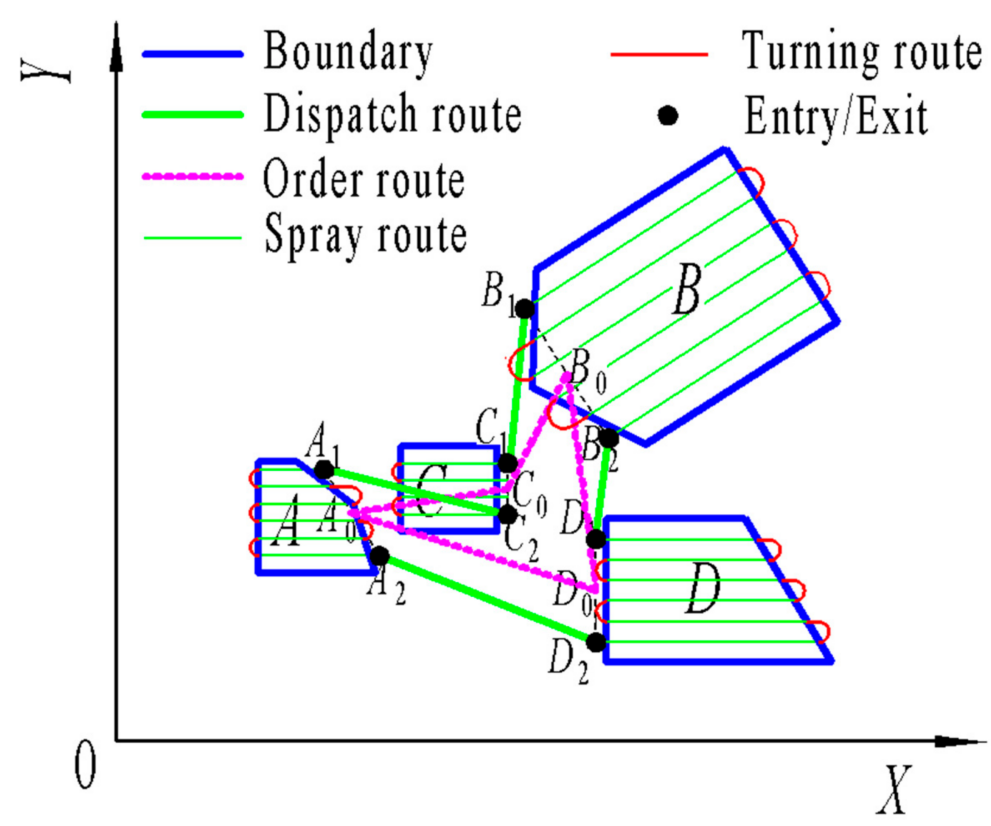

Figure 2. The spraying operation plan.

Solving the global dispatch route is similar to the traveling salesman problem (TSP), an NP-hard problem [28]. The difference is that the helicopter must complete its pesticide application in one zone before it moves to the next zone. This makes it more difficult than TSP because some paths are not allowed. We consider solving this problem in two steps. First we solve for the operation order and then we determine the sequence of entry and exit points for each forest area. The latter is equal to the dispatch route as mentioned above.

Meta-heuristic algorithms are widely used for solving NP-hard problems and are classified into two dominant classes: evolutionary and swarm intelligence techniques. Evolutionary algorithms mimic the concept of evolution in nature [29,30]. The best and most suitable algorithm in this class is the genetic algorithm (GA) [29]. Swarm intelligence techniques mimic the intelligence of swarms, herds, schools, or flocks of creatures in nature. One of the most popular algorithms in this class is the ant colony optimization algorithm (ACO) [29]. Numerous studies have shown that GA is strong in global search and poor in local search, while ACO is the opposite, with its strong in local search and poor in global search [31-33]. A fusion of GA and ACO algorithms can make better use of the advantages of both algorithms [34,35].

With reference to "No free lunch theorems" and the concept of divide-and-conquer [31], a two-layer intelligent algorithm is proposed to obtain the dispatch route. The first layer of the algorithm combines the GA and ACO algorithm [35,36]. It finds feasible solutions for the operation order. The second layer of the algorithm is a GA that determine the sequence of entry and exit points for each area. This two-layer algorithm is called GAACO-GA, and its flow chart is shown in Figure 3. Since the first layer solves a TSP problem, any algorithm suitable for TSP can be used. In addition to the GA and ACO algorithms, particle swarm optimization (PSO) and simulated annealing (SA) algorithms are also suitable for TSP. Therefore, the first layer can also use the GA [37], SA [38], ACO [39,40], and PSO 
algorithms [41-44]. Four intelligent two-layer algorithms (GA-GA, SA-GA, ACO-GA, and PSO-GA) are compared with the proposed GAACO-GA algorithm. In the following we only present the GAACO-GA algorithm. The other four algorithms are similar to that.

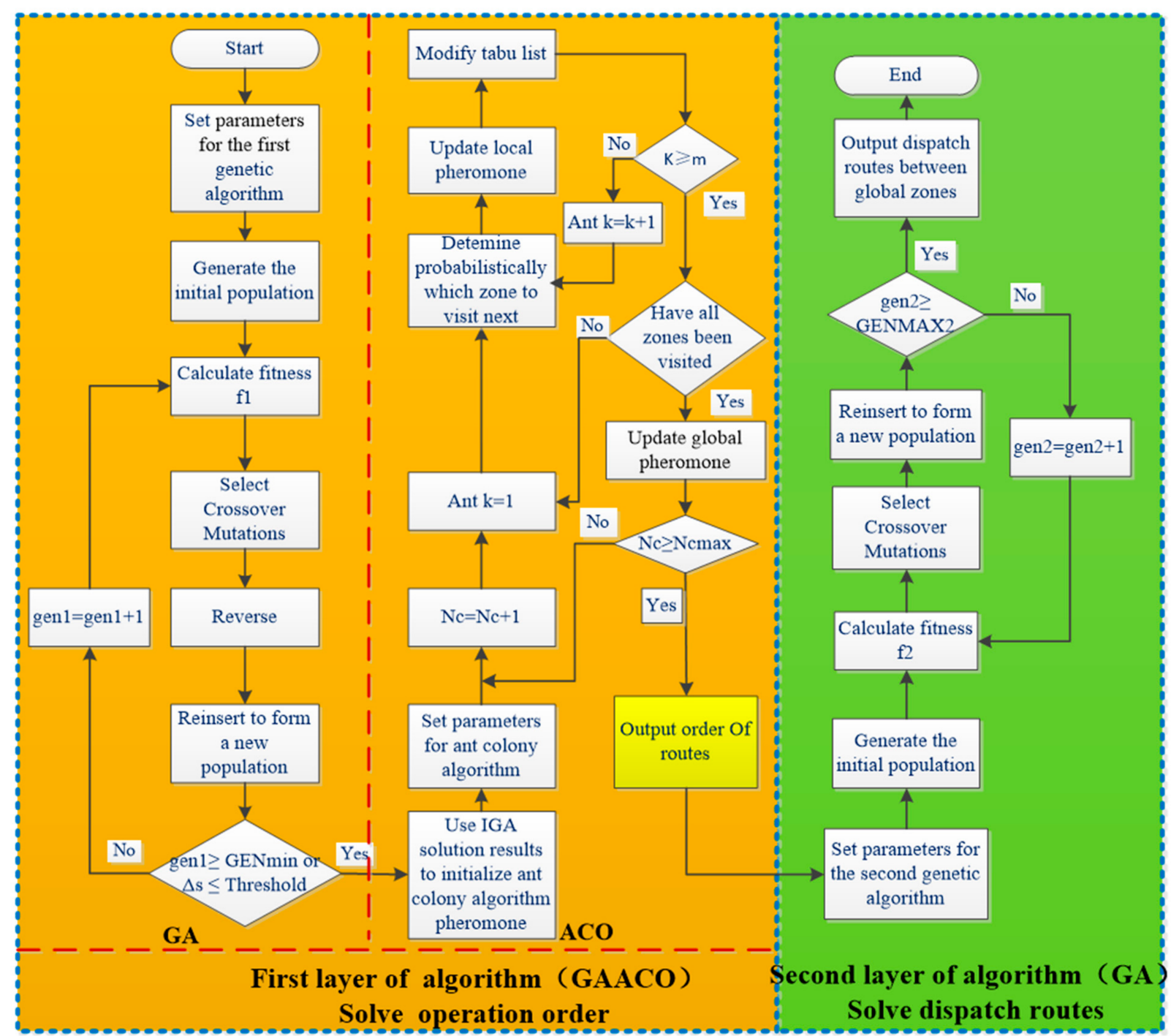

Figure 3. Flow chart of the intelligent two-layer algorithm for calculating the global dispatch route.

\subsubsection{The First Layer of GAACO-GA}

In this layer, our goal is to obtain a set of better operation orders, containing the shortest orders. We use GA to obtain the better operation orders, and ACO to obtain the shortest orders. Then we put the results into the one population. The results of the GA are used for pheromone initialization to increase the search speed of the ACO algorithm $[34,35]$.

(1) Using the GA to obtain better operation orders

The GA is a global search algorithm based on natural selection and evolutionary mechanisms and simulates the genetic evolution of organisms [37]. We use integer coding to define the spraying areas and the airport. Then we use Equation (9) to calculate the fitness value by means of crossover operations, mutation operations, and reversal operations, the population is updated. Finally, the paths with large fitness values (shorter operation orders) are retained. The set of operation orders in the last population is what we need.

$$
f_{1}=\frac{1}{\sum_{i=1}^{n-1} D_{i j}+D_{1 n}}
$$


where $D_{i j}$ is the distance from the application region $i$ to the application region $j, j=i+1$; $f_{1}$ is the fitness function, which is the reciprocal of the distance from the start node to the end node then back to the start node after passing through all nodes.

In particular, a reversal operator is incorporated into the traditional GA to prevent the population from losing diversity prematurely and falling into a local optimum solution. It works like this. If the code string is 12345678, and two breaks occur between 2 and 3 and between 6 and 7, the number between the two break positions is reversed so that the new code string is $12-6543-78$.

GAs tend to stagnate near the optimal solution when solving TSP problems, so that a set of better operation order solutions can be obtained. A more powerful intelligent algorithm is still required for the acquisition of the shortest operation order. Among these algorithms, the ACO algorithm was chosen.

(2) Using ACO to obtain the shortest operation order

The ACO algorithm emulates the behavior of ant colonies moving from their nest to food sources. Ants can find the shortest route from the food source to their anthills without using their sense of sight $[38,39]$. Since the ACO algorithm is similar to a greedy algorithm at the beginning of the operation and operates blindly, the solution to the TSP obtained from the GA is used for the pheromone initialization of the ACO algorithm. The principle is as follows. For example, when the GA obtains a result with a path sequence of 2-5-7, the pheromone of that path is increased correspondingly. The algorithm starts, executes the first loop, and randomly places $m$ ants on $n$ nodes. The probability of the $k$ th ant moving from node $i$ to node $j$ as a result of being attracted by the pheromones is given by Equation (10). The local pheromone level of the path between nodes $i$ and $j$ is updated using Equation (11). Ant $k$ starts at node $j$ and continues to search for the next node until it has visited all nodes. All $\mathrm{m}$ ants traverse all nodes in the same way as ant $\mathrm{k}$. When all ants have completed their routes, the global pheromone level is updated. The global pheromone update rule uses only the pheromone level of the ant moving on the optimal path after each loop, as shown in Equation (12). At this point, the first loop ends, and the next loop starts, again placing $m$ ants randomly at $n$ nodes. The algorithm ends when the set number of cycles has been reached. The pheromones level is limited, as shown in Equations (13)-(15) to prevent an excessive local pheromone level from affecting the global search capability. The optimal path length obtained by the GA is used as the benchmark for setting the pheromone level.

$$
\begin{gathered}
P_{i j}^{k}=\left\{\begin{array}{l}
\frac{\left[\tau_{i j}\right]^{\alpha}\left[\eta_{i j}\right]^{\beta}}{\sum_{u \text { allowed }_{k}}\left[\tau_{i u}\right]^{\alpha}\left[\eta_{i u}\right]^{\beta}}, j \in \text { allowed }_{k} \\
0, \text { otherwise }^{\prime}
\end{array}\right. \\
\tau_{i j}(t+n)=(1-\rho) \tau_{i j}+\rho \tau_{0}
\end{gathered}
$$

where $\tau_{i j}$ is the pheromone level at edge $\mathrm{E}(i, j), \eta_{i j}(\mathrm{t})$ is the heuristic factor, $\eta_{i j}(\mathrm{t})=1 / d_{i j}, d_{i j}$ is the distance between node $i$ and $j$. allowed $_{k}$ is the set of pesticide application areas that ant $\mathrm{k}$ is allowed to visit next. $\rho$ is the pheromone volatility factor, less than $0.5 . m$ is the number of ants. $\alpha$ is the pheromone heuristic factor. $\beta$ is the expected heuristic factor. $q$ is a random variable uniformly distributed in interval [0,1]. $Q$ is a pre-determined parameter that determines the relative importance of using prior knowledge and exploring new paths, 
$0 \leq Q \leq 1 . D_{n n}$ is the optimal path obtained by the GA using this value as a benchmark for the maximum and minimum pheromone level. $\tau_{0}$ is the length of the shortest path obtained from the GA, $\tau_{0}=1 / D_{n n} . a>1$ is an interval factor that controls the interval range, and $a \leq 1 / \rho . \tau_{i j} \in\left[\tau_{\min }, \tau_{\max }\right]$ holds true at all times, and $\tau_{i j}(0)=\left(\tau_{\max }+\tau_{\min }\right) / 2$.

In summary, the pheromone initialization utilized the results of the GA, using the strategy of the elite ants when updating the global pheromone and limiting the pheromone size at all times. With the use of these strategies, the ACO algorithm is able to quickly focus on the superior paths and is further enhanced in terms of the speed and global seeking capability.

\subsubsection{The Second Layer of GAACO-GA}

The second layer of GAACO-GA uses a GA to obtain the global dispatch route considering the enter/exit points of the multiple forest areas. A binary code is used, and the chromosome length is the number of forest areas plus one; the latter point indicates the airport. The fitness of each chromosome is calculated using Equation (16). As described previously, the first layer of the algorithm provides a set of feasible operation orders containing $n$ paths with different sequences. If chromosome $(i,:)$ is the $i$ th chromosome in the population of the GA in this layer, each operation order is adjusted to chromosome $(i,:)$ according to the location of the entry/exit points, and $n$ global dispatch routes are obtained. The distances of all $n$ global dispatch routes are calculated, and the minimum distance is obtained. The reciprocal of this minimum value is used as the fitness value of the chromosome ( $i$, :). As shown in Figure 2, the operation order is assumed to be $A B C D$. Region A may have an entry point at $A_{1}$ and an exit point at $A_{2}$ or vice versa. The two states are represented by 0 and 1 , respectively. Therefore, the state code of the sequence $A_{1} A_{2} B_{1} B_{2} C_{1} C_{2} D_{1} D_{2}$ is 0000 , and that of the sequence $A_{1} A_{2} B_{2} B_{1} C_{1} C_{2} D_{2} D_{1}$ is 0101 . The fitness value of chromosome 0101 can be found by replacing chromosome $(i$, :) in Equation (16) with 0101 . Similarly, the chromosomes in the population are continuously optimized through crossover and mutation operations. Finally, the chromosome corresponding to the shortest dispatch route is preserved and its shortest dispatch route is determined.

$$
f_{2}=\frac{1}{\min \left(l_{1(\operatorname{chromosome}(i,:))}, l_{2(\operatorname{chromosome}(i,:))}, \ldots, l_{n(\operatorname{chromosome}(i,:))}\right)}
$$

where $l_{i(\text { chromosome }(i,:))}$ denotes the length of the global dispatch route path adjusted according to chromosome $(i,:)$ for the $i$ th row of the path $l_{i}$ in the operation order set obtained by GAACO.

\subsection{Evaluation Metrics of the Scheduling Algorithms}

To evaluate the performance of a scheduling algorithm, specific indicators need to be used. Since the algorithm is a stochastic intelligent optimization algorithm, the results may be different even if the algorithm starts at the same point [29]. However, the main advantage of stochastic algorithms over deterministic algorithms is that they prevent finding locally optimal solutions [29]. For practical applications, it is desirable that the algorithm has a short running time to provide optimal results and operates stably. Therefore, three evaluation metrics are used to determine the algorithm's performance: the average search time, the optimal solution in a finite number of runs, and the robustness. Among these metrics, the most important one is the optimal solution, so this metric should be considered first.

The average search time of the algorithm is defined as follows:

$$
t=\frac{1}{m_{0}} \sum_{i=1}^{m_{0}} t_{i}
$$

where $m_{0}$ is the number of running times of the algorithm, and $t_{i}$ is the time cost for each run. 
The optimal solution in a finite number of runs is defined as follows:

$$
s_{\text {best }}=\min \left(s_{i}\right)
$$

where $s_{\text {best }}$ is the global optimal solution obtained by the algorithm, and $s_{i}$ is the solution obtained after each implementation of the algorithm.

The algorithm robustness is defined as follows:

$$
\sigma_{s}=\sqrt{\frac{1}{m_{0}-1} \sum_{i=1}^{m_{0}}\left(s_{i}-\frac{1}{m} \sum_{i=1}^{m_{0}} s_{i}\right)^{2}}
$$

\subsection{Self-Built Multi-Forest Test Environment}

Although the algorithm has been designed, we also need a multi-forest area environment to test the algorithm. In addition, many parameters of the algorithm are also related to the number of forested areas. First estimate the acreage of helicopter operations, then determine the number of forest areas and construct a hypothetical operational task map.

First, we calculate the pesticide application area based on the helicopter's endurance voyage.

$$
A_{1}=1000 S_{v} W_{s}
$$

Second, we calculate the pesticide application area based on the weight of the load.

$$
A_{2}=\frac{10000 m_{d}}{\rho_{d} V_{p h}}
$$

Third, we calculate the pesticide application aera based on the helicopter's endurance time.

$$
A_{3}=1000 v_{0} T_{b} W_{s}
$$

The working area is the smallest of the three calculated areas.

$$
A=\min \left(A_{1}, A_{2}, A_{3}\right)
$$

where $S_{v}$ is the maximum travel distance of the helicopter, $\mathrm{km} ; W_{s}$ is the spraying width, $\mathrm{m} ; m_{d}$ is the weight of the pesticide, $\mathrm{kg} ; \rho_{d}$ is the density of the pesticide, $\mathrm{g} / \mathrm{cm}^{3} ; V_{p h}$ is the pesticide application rate per hectare, $\mathrm{L} / \mathrm{hm}^{2} ; v_{0}$ is the helicopter speed during the spraying operation, $\mathrm{km} / \mathrm{h} ; T_{b}$ is the helicopter's endurance during the spraying operation, $\mathrm{h} ; \mathrm{A}$ is the total operating area, $\mathrm{m}^{2}$.

We use the Thunderbird R44 helicopter as an example. It is commonly used for spraying operations in forest areas. We estimate the operation area of this aircraft and create a scenario map with multiple forest areas to be sprayed. Table A1 lists the parameters of the Thunderbird R44 Helicopter [23]. We use the spraying operation parameters provided in Ref. [23] as an example; the parameters are listed in Table A2. The calculated operation area is $\mathrm{A}=60$ hectares. We consulted experienced helicopter pilots and the literature and found that the acreage of a single forest area is usually not less than $3.3 \mathrm{ha}$. Thus, the R44 can cover up to 18 areas in one flight. The algorithm parameters are based on this information. We created a map using these parameters (Figure A1; including 18 forest areas of approximately 3.3 hectares each). The coordinates of the vertices of all forest areas are shown in Table A3.

\subsection{Test Equipment}

Field experiments were carried out to compare the performance of the proposed algorithm with manual empirical methods under practical conditions. The test was conducted using a Robinson Helicopter (Thunderbird model R44) supplied by Jiangsu Ningxiang General Aviation Company, with an average fuel consumption of $57 \mathrm{~L} / \mathrm{h}$. The spray width 
was $20 \mathrm{~m}$, and the pesticide consumption was $10 \mathrm{~L} / \mathrm{km}$ [23]. A variable application monitoring system [25] was developed to monitor the trajectory and control the application volume in real time. The device was located in the cab during the test. The photos of the experiment are shown in Figure 4.

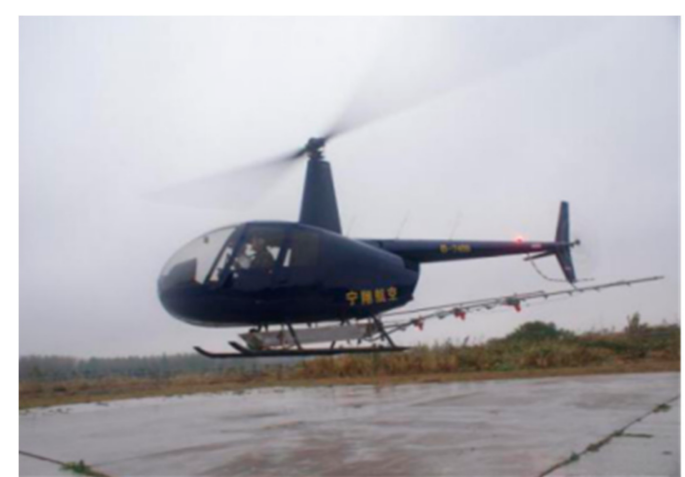

(a)

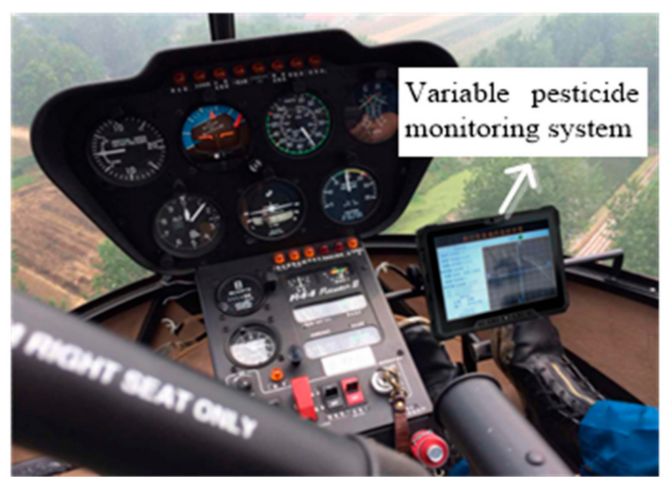

(b)

Figure 4. Test equipment. (a) R44 helicopter; (b) The variable application monitoring system in the helicopter.

\section{Results}

Simulation experiments were carried out on a self-constructed multi-forest environment. Then a live flight experiment was carried out in the woodland.

\subsection{Algorithm Verification Using a Self-Constructed Multi-Forest Environment}

Applying the full coverage algorithm described in Section 2.1 above in individual forest areas in Figure A1 in the Appendix A, we can obtain the application route map as shown in Figure 5. The black circles indicate the airport. We have zoomed in three times on one of the areas, $\mathrm{K}$, to make it easier to see the routes within the area. All other areas are similar. Once the planning was complete, the coordinates of the entry and exit points for each forest area were determined. The entry and exit point coordinates are shown in Table A4 in the Appendix A.

Five two-layer intelligent algorithms (GA-GA, SA-GA, ACO-GA, PSO-GA, and GAAC O-GA) were used to solve the scheduling task shown in Figure 5, and their performances were compared. Each algorithm was run 20 times to reduce errors. The various algorithm parameters were set as follows: in GAACO-GA, GA in the first layer: population size $\mathrm{N}=100$; variation probability $P_{m}=0.005$; the maximum number of iterations $M A X G E N=500$. ACO algorithm in the first layer: number of ant colonies $m=30$, the maximum number of iterations NC_max $=500$; pheromone volatility factor $\rho=0.1$; pheromone intensity $Q=100$; pheromone heuristic factor $\alpha=1$; expected heuristic factor $\beta=5$. GA in the second layer: population size $N I N D=50$, crossover probability $P_{c 2}=0.9$; variation probability $P_{m 2}=0.005$; the maximum number of iterations $M A X G E N_{2}=2000$. In GA-GA, the maximum number of iterations $M A X G E N=1000$. In SA-GA, the main parameters of the SA algorithm included a cooling rate of 0.9 , initial temperature of $1000^{\circ} \mathrm{C}$, and final temperature of $0.001{ }^{\circ} \mathrm{C}$. In ACO-GA, it was the same as the GAACO-GA. In the PSO algorithm of PSO-GA, the number of individuals was 200, and the number of evolutionary generations was 500. The results obtained from the five algorithms are listed in Table 1.

The results show that the GAACO-GA provides a global route length of $5032.75 \mathrm{~m}$, which is $5.60 \%, 5.45 \%, 6.54 \%$, and $4.07 \%$ shorter than that obtained from the GA-GA, SA-GA, ACO-GA, and PSO-GA, respectively. The average optimal solution is also shorter than the other four algorithms. The average search time is faster than that of the GA-GA, GA-GA, ACO-GA, and PSO-GA. 
The dispatch routes solved by the five algorithms, and their corresponding operation orders, are shown in Figure 6. The dispatch routes are shown as the thick blue solid line on the left and the operation orders are shown as the thin blue solid line on the right.

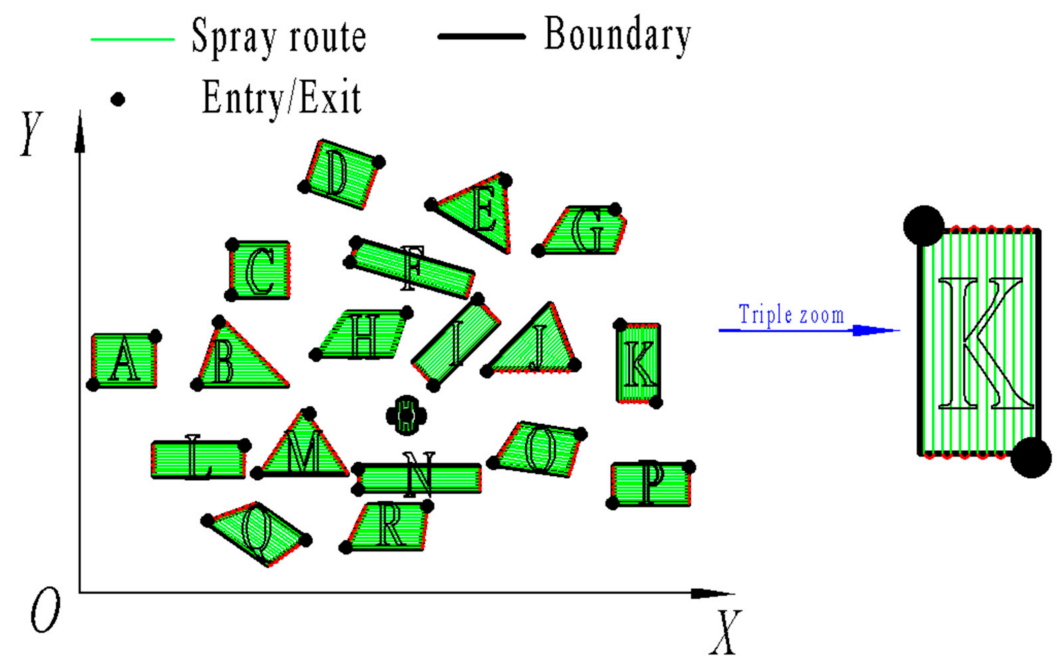

Figure 5. Map showing multiple forest areas, the spray route, and the entry/exit points based on the proposed algorithm.

Table 1. Comparison of the performance of the five algorithms.

\begin{tabular}{cccccc}
\hline Algorithm & GA-GA & SA-GA & ACO-GA & PSO-GA & GAACO-GA \\
\hline Optimal Solution (m) & 5314.53 & 5307.18 & 5361.89 & 5237.72 & 5032.75 \\
Average Optimal & 5667.99 & 5806.81 & 5505.26 & 5448.92 & 5254.29 \\
Solution (m) & 16.88 & 25.12 & 7.86 & 15.71 & 7.82 \\
Average Search Time (s) & 216.74 & 229.34 & 181.14 & 161.11 & 153.85 \\
Algorithm Robustness & & & &
\end{tabular}

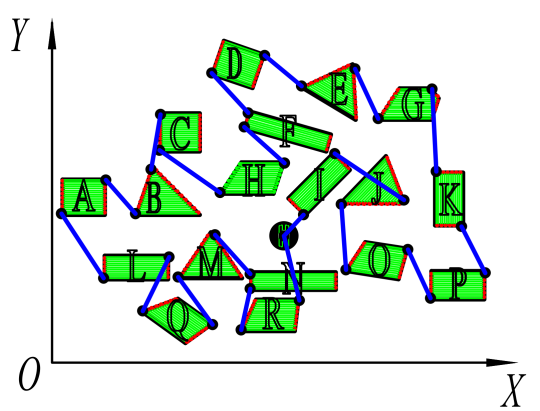

(a)

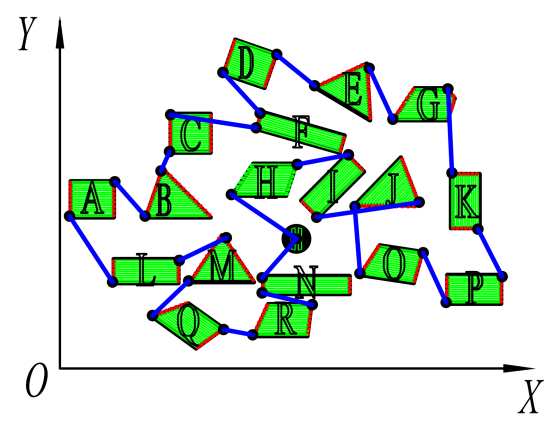

(c)

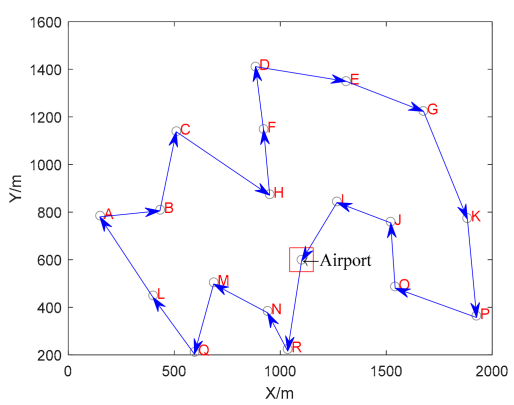

(b)

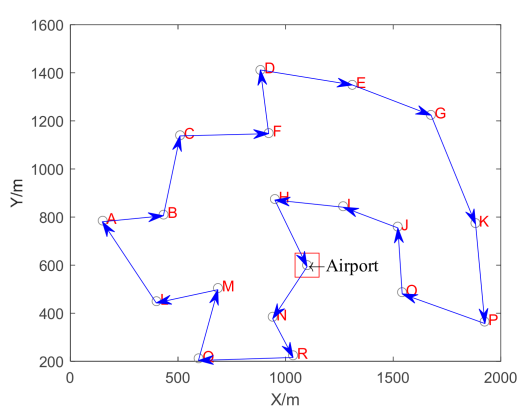

(d)

Figure 6. Cont. 


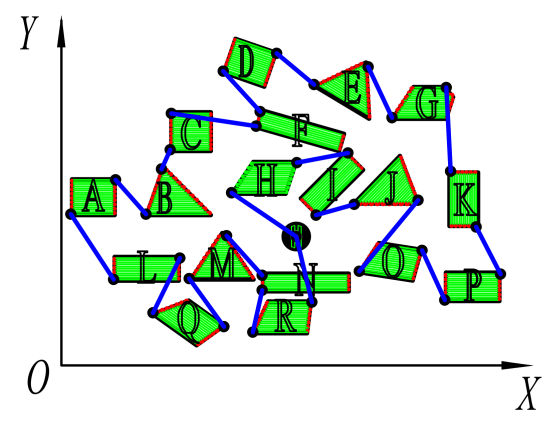

(e)

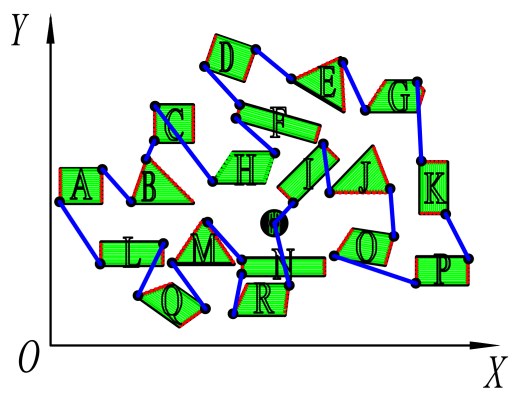

(g)

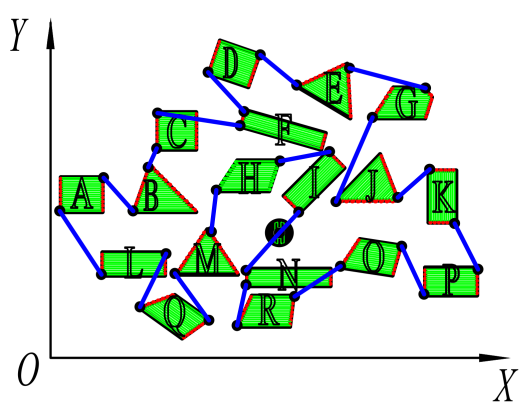

(i)

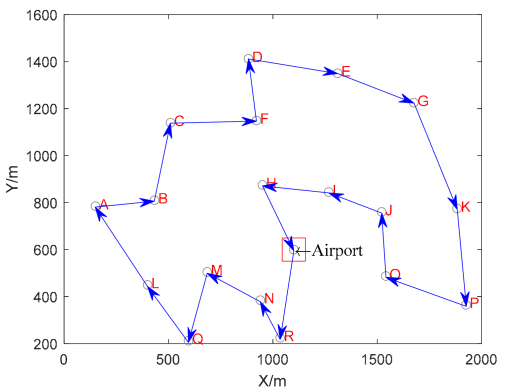

(f)

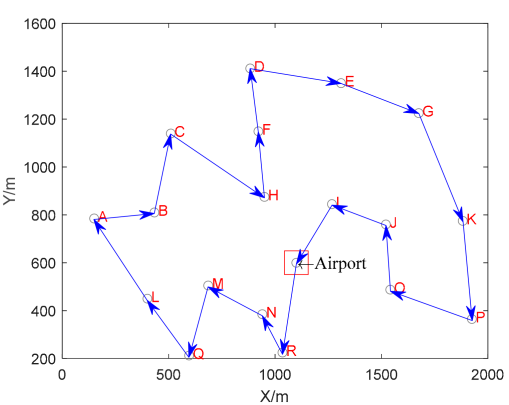

(h)

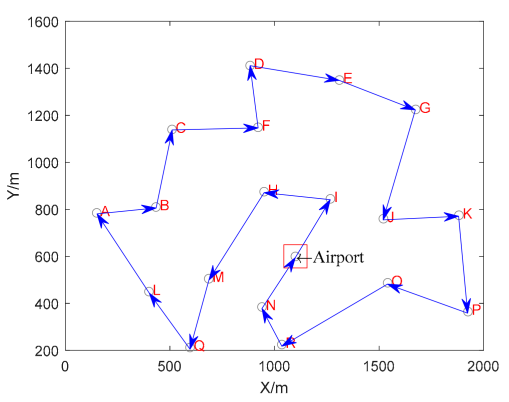

(j)

Figure 6. The operation orders and dispatch routes obtained from five algorithms. (a) The dispatch routes solved by GA-GA(5314.53m); (b) The operation orders corresponding to the dispatch routes solved by GA-GA(6522.32m); (c) The dispatch routes solved by SA-GA $(5307.18 \mathrm{~m})$; (d) The operation orders corresponding to the dispatch routes solved by SA-GA(6508.33m); (e) The dispatch routes solved by ACO-GA(5361.89m); (f) The operation orders corresponding to the dispatch routes solved by ACO-GA(6479.91m); (g) The dispatch routes solved by PSO-GA(5237.72m); (h) The operation orders corresponding to the dispatch routes solved by PSO-GA(6522.32m); (i) The dispatch routes solved by GAACO-GA(5032.75314.53m); (j) The operation orders corresponding to the dispatch routes solved by GAACO-GA(6909.83m).

\subsection{Field Experiments}

Field experiments were carried out to compare the performance of the proposed algorithm with manual empirical methods under practical conditions. The test area was located near Pigzui Mountain in Xuyi County, Huai'an City, Jiangsu Province. The combined area of the five sites was 18.2 ha (Figure 7a). The latitude and longitude coordinates of the forest areas are listed in Table A5. The coordinates of the aircraft take-off and landing point are $\left(118^{\circ} 23^{\prime} 31^{\prime \prime}, 32^{\circ} 49^{\prime} 41^{\prime \prime}\right)$, as shown in the red circle in Figure 7a. 


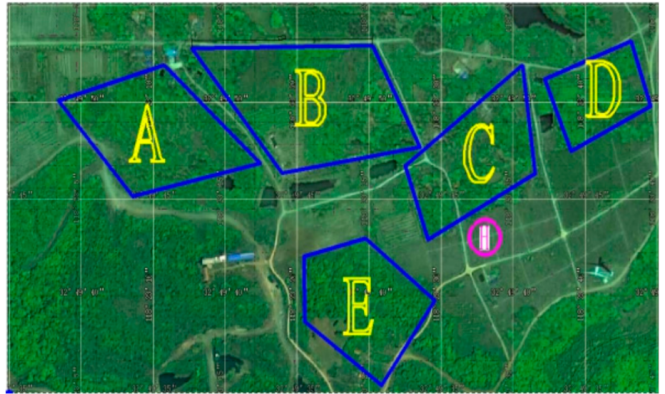

(a)

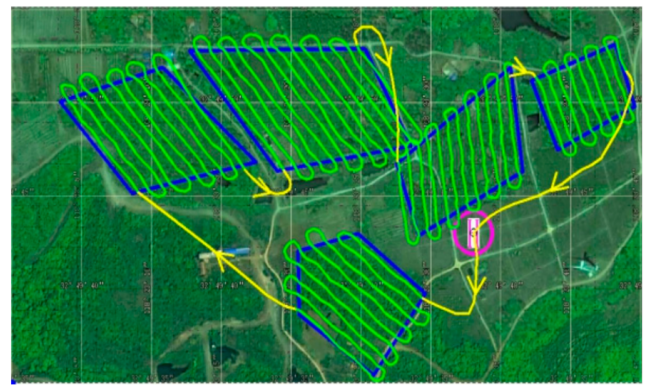

(c)

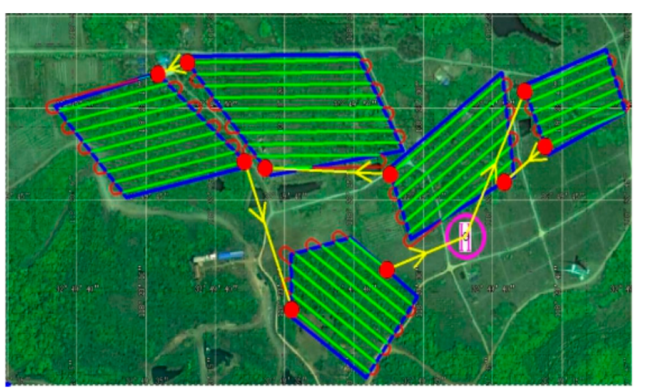

(b)

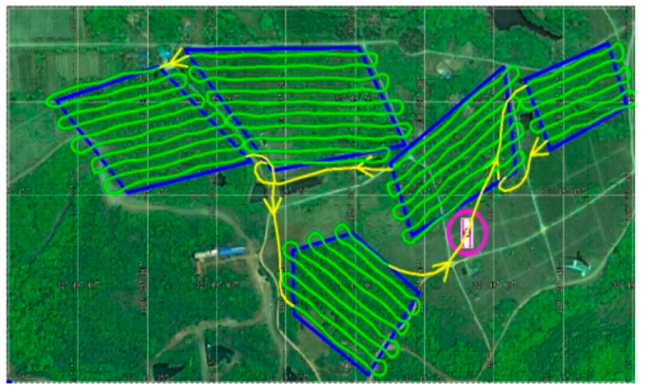

(d)

Figure 7. Comparison of the routes obtained from the proposed GAACO-GA algorithm and the manual empirical method. (a) Five forest areas selected for spraying; (b) The planned route obtained from the GAACO-GA algorithm; (c) The actual flight path based on the manual empirical method; (d) The actual flight path based on the GAACO-GA algorithm.

The manual empirical method and the proposed algorithm were used to plan the route. The results are shown in Figure 7 . Figure $7 \mathrm{~b}$ shows the planned route obtained from the GAACO-GA algorithm, and the actual flight paths based on the manual empirical method and the proposed algorithm are shown in Figure $7 \mathrm{c}, \mathrm{d}$, respectively. The manual empirical method is typically used by companies to plan the route based on experience. The route is approximated to achieve a consistent heading on the route and choose the shortest route to reach the next patch. The route planning was conducted offline using a Lenovo Zhaoyang K43c-80 business laptop, and the data were imported into the variable application monitoring system. The laptop had an Intel Core i7-8550U processor, $1.8+2.0 \mathrm{GHz}, 8 \mathrm{~GB}$ of RAM, and a 64-bit Win10 genuine system. Table 2 lists the results of the two methods.

Table 2. Quantitative results obtained from the GAACO-GA algorithm and the manual empirical method for route planning.

\begin{tabular}{|c|c|c|c|c|c|c|}
\hline Algorithm & $\begin{array}{l}\text { Length of Pesticide } \\
\text { Application Path (m) }\end{array}$ & $\begin{array}{l}\text { Length of Dispatch } \\
\text { Route (m) }\end{array}$ & $\begin{array}{c}\text { Number of } \\
\text { Turnarounds }\end{array}$ & $\begin{array}{c}\text { Extra Coverage } \\
\text { Rate }(\%)\end{array}$ & $\begin{array}{c}\text { Fuel } \\
\text { Consumption (L) }\end{array}$ & $\begin{array}{c}\text { Pesticide } \\
\text { Consumption (kg) }\end{array}$ \\
\hline $\begin{array}{l}\text { Actual flight path } \\
\text { based on the } \\
\text { manual empirical } \\
\text { method }\end{array}$ & $12,560.294$ & 1503.748 & 51 & $10.29 \%$ & 8.57 & 125.6 \\
\hline $\begin{array}{l}\text { Planned path } \\
\text { obtained from } \\
\text { GAACO-GA }\end{array}$ & 9972.793 & 1086.66 & 40 & $7.94 \%$ & - & - \\
\hline $\begin{array}{l}\text { Actual flight path } \\
\text { based on } \\
\text { GAACO-GA }\end{array}$ & $11,913.184$ & 1286.065 & 40 & $8.73 \%$ & 7.76 & 119.131 \\
\hline
\end{tabular}

The results show that the length of the pesticide application path planned by the GAACO-GA algorithm is $9972.793 \mathrm{~m}$, and the dispatch route is $1086.66 \mathrm{~m}$. The actual pesticide application path based on this algorithm has a length of $11,913.184 \mathrm{~m}$, and the dispatch route is $1286.065 \mathrm{~m}$, both of which are longer than the planned path. However, the 
number of turnarounds is 40 for the planned and actual flights. In summary, it seems more meaningful to compare the actual flight paths obtained from the GAACO-GA algorithm and the manual empirical method since external influencing factors are excluded. The actual flight path based on the manual empirical method has a pesticide application path of $12,560.294 \mathrm{~m}$, a dispatch route of $1503.748 \mathrm{~m}, 51$ turnarounds, an extra coverage rate of $10.29 \%$, fuel consumption of $8.57 \mathrm{~L}$, and pesticide consumption of $125.6 \mathrm{~kg}$. The actual flight path based on the proposed algorithm is $5.43 \%$ shorter than that based on the manual empirical method. The dispatch route length is $16.93 \%$ shorter, the number of turnarounds was reduced by 11 times, and the extra coverage rate was reduced by $17.87 \%$. Aviation fuel consumption and pesticide consumption are reduced by $10.56 \%$ and $5.43 \%$, respectively.

\section{Discussion}

\subsection{Analysis of Pesticide Spraying Routes of a Single Forest Area}

The pesticide spraying routes in the area planned according to the algorithm proposed in this paper are shown in Figure 5. From Figure 5, almost all of the routes were planned to start from the longest side of a single forest area, which resulted in fewer turnarounds. There were triangles, quadrilaterals, and pentagons in the forest areas. Pesticide spray routes in triangular forest areas inevitably produced many shorter single spray routes, which was better in quadrilateral and pentagonal shapes with two parallel sides. It is suggested that, where possible, when dividing large forest areas, the application area should be divided into polygons with two parallel sides where possible, and it is better to have longer parallel sides. By this way the routes were planned so that there fewer turnarounds, and the individual routes were usually longer, which were more suitable for helicopters to follow. The division of forest areas into triangles was strongly discouraged. In Ref. [21], which are planned routes for UAVs, they contain a large number of shorter single routes, with a large number of additional turnarounds, and the routes change in height depending on the terrain. Obviously, such a route would be very difficult to track for a helicopter flying at high speed. Therefore, it was not possible to apply the routes planned by the UAV directly to the helicopter.

\subsection{Analysis of Scheduling Algorithms for Multiple Forest Areas}

Judging from Table 1, compared with the other four two-layer intelligence algorithms, the results of the GAACO-GA algorithm solution have some advantages. Since offline planning was conducted, the average search time did not have a significant impact. The most important metric was the scheduling route length. The reason for the better performance of the GAACO-GA is that the results in the first layer contain both the shortest operation order and a sufficient number of other feasible operation orders, which was the design intent of the two-layer algorithm. The other four algorithms use a signal algorithm for the set of operation orders, which do not work as well as GAACO.

The dispatch routes for the multiple forest areas solved by different algorithms are shown in Figure 6. Judging from Figure 6, we find an interesting phenomenon. The length of operation order path was not proportional to the length of the dispatch route. In other words, the dispatch route corresponding to the shortest operation order may not be the shortest, especially for a large number of forest areas.

An algorithm that solved a similar problem had been described in Ref. [19], which was published in a top Chinese journal. In Ref. [19], the shortest sequence order is first solved for and then the global scheduling path is after. The algorithm designed by this idea will be compared with the algorithm proposed in this paper. It is obvious that the results of solving with this approach will be consistent with Figure 6e,f. It is clear that the algorithm in this paper is better.

\subsection{Analysis of Field Experiment}

The actual flights were carried out with a variable application monitoring system developed by the team and operated by the same pilot. Judging Figure $7 \mathrm{~b}$, $\mathrm{d}$ and Table 2, the actual pesticide application path and the dispatch routes are longer than the planned path. 
There are two main reasons. First, the proposed algorithm does not plan the turnaround route; thus, its length was not included in the calculation of the application path. In the actual flight, the application path included the length of the turnarounds. Second, the planned pesticide application patch and dispatch route were straight lines. However, in practice, the flight path was not perfectly straight due to operational factors, weather, and wind. Thus, the flight path was slightly longer than the planned path. In a small area, the deviation between the planned and actual flight paths was within acceptable limits. However, in larger areas, this discrepancy should be considered and will be analyzed in a further study.

Figure 7c shows the actual flight paths planned by the experienced pilot team according to the empirical method, representing the highest level of the company. Figure $7 \mathrm{~d}$ shows the actual flight path based on the algorithm in this paper. In order to exclude the influence of experimental factors, this paper focuses on comparing the differences in the real flight paths. The algorithms in this paper have significantly fewer turnarounds on the actual flight routes, less excess coverage, shorter application and dispatch routes, and reduced aviation fuel consumption and pesticide consumption. It can be inferred that the algorithm proposed in this paper has a significant advantage over the manual empirical method for planning pesticide application routes.

\subsection{Application Prospects and Limitations}

When the number of forest areas increases and the size of the forest area increases, it becomes much more difficult to delineate a reasonable pesticide spray route by manual empirical regulations. However, it is easy to solve these problems with algorithms in this paper that are independent of the size and the number of forest areas. We are convinced that the algorithms in this paper have good prospects for application to the difficult problems of forest pest and disease control.

Nevertheless, the route planning in this paper, which is carried out on a two-dimensional plane, is mainly aimed at operational forest areas that are plantations with little change in elevation. The route planning was mainly suitable for helicopters that operate at high speeds. In the case of ecological forest areas containing large slopes, such as the Dabie Mountains, further route planning in three dimensions will need to be considered, at which point both the route planning method and the route monitoring system will need to be improved and designed. In addition, the airport was pre-selected in this paper. The algorithm cannot be used to plan an optimal airport or estimate fuel consumption and pesticide consumption. Moreover, the division of large forest areas into smaller patches based on no-fly zones such as fishponds, and the utilization of multiple aircraft types are worthy of further in-depth studies. Future route planning will therefore need to take further account of helicopter speed and energy consumption characteristics to further meet the needs of smart forestry management.

\section{Conclusions}

At present, China has a very large forest area. The use of helicopters for pesticide application to control pests and diseases is one of the most important methods. However, route planning of pesticide application in China still relies mainly on the pilot's flight experience and there is no strict scientific route planning method so far. Therefore, this paper investigates the route planning method for helicopter pesticide application.

When the helicopter is conducting spraying operations in multiple forest areas, the routes are divided into two parts: pesticide spraying routes for individual forest areas and dispatch routes between multiple forest areas. First, the shorter spraying route with fewer turnarounds for individual forest areas was determined. Then a two-layer intelligent algorithm was designed to determine the dispatch route between multiple forest areas, which is referred to as GAACO-GA. A pesticide spraying experiment was conducted with a helicopter. It was verified that the algorithm in this paper plans the path and outperforms the manual empirical method. It was found that the length of actual pesticide application 
routes and the global dispatch route, the number of turnarounds, the extra coverage rate, the aviation fuel consumption, and the pesticide consumption were all reduced to a certain degree, compared with the manual empirical method. We also found that the dispatch route corresponding to the shortest operation order may not be the shortest, which we believe can provide guidance for the future scheduling algorithm developers.

We believe that the method in this paper can provide a technical reference for the world's helicopter pest control route planning. In future, to meet the needs of smart forestry management, it will be better to further consider the reasonable division of forest areas, helicopter speed and energy consumption characteristics when planning the routes for helicopters.

Author Contributions: Conceptualization, S.F. and Y.R.; methodology, S.F.; software, S.F.; validation, Y.L.; formal analysis, C.H.; investigation, S.F.; resources, S.F.; data curation, X.C. and B.L.; writingoriginal draft preparation, S.F.; writing - review and editing, S.F.; visualization, S.F.; supervision, Y.R.; project administration, Y.R.; funding acquisition, Y.R. All authors have read and agreed to the published version of the manuscript.

Funding: This research was funded by National Key Research and Development Program of China, grant number 2018YFD0600202-04, and Key Research and Development Program of Anhui Province, grant number 202104a06020001.

Institutional Review Board Statement: Not applicable.

Informed Consent Statement: Not applicable.

Data Availability Statement: The data presented in this study are available on request from the corresponding author. The data are not publicly available due to privacy.

Acknowledgments: Thanks to Jiangsu Ningxiang General Aviation Company for providing Robinson Helicopter (Thunderbird model R44). Sincerely thank the Chinese government for the flight permit.

Conflicts of Interest: The authors declare no conflict of interest. The funders had no role in the design of the study; in the collection, analyses, or interpretation of data; in the writing of the manuscript, or in the decision to publish the results.

\section{Appendix A}

Table A1. Parameters of the Thunderbird R44 Helicopter.

\begin{tabular}{|c|c|c|c|c|c|}
\hline $\begin{array}{l}\text { Helicopter Fuselage } \\
\text { Length (m) }\end{array}$ & $\begin{array}{l}\text { Helicopter Wingspan } \\
\text { Length (m) }\end{array}$ & $\begin{array}{l}\text { Maximum Take-Off } \\
\text { Weight (kg) }\end{array}$ & $\begin{array}{l}\text { Cruising Speed } \\
\left(\mathbf{k m} \cdot \mathrm{h}^{-1}\right)\end{array}$ & $\begin{array}{l}\text { Rout Length } \\
(\mathbf{k m})\end{array}$ & $\begin{array}{l}\text { Endurance } \\
\text { (h) }\end{array}$ \\
\hline 9 & 10.1 & 1134 & 204 & 404 & 3.5 \\
\hline
\end{tabular}

Table A2. Spraying operation parameters.

\begin{tabular}{|c|c|c|c|c|c|c|}
\hline $\begin{array}{l}\text { Operating } \\
\text { Height (m) }\end{array}$ & $\begin{array}{l}\text { Operating Speed } \\
\left(\mathbf{k m} \cdot \mathrm{h}^{-1}\right)\end{array}$ & $\begin{array}{c}\text { Amount of } \\
\text { Pesticide Applied } \\
\text { Per Hectare } \\
\left(\mathrm{L} \cdot \mathrm{hm}^{-2}\right)\end{array}$ & $\begin{array}{l}\text { Spraying } \\
\text { Width (m) }\end{array}$ & $\begin{array}{c}\text { Maximum } \\
\text { Spray Time (h) }\end{array}$ & $\begin{array}{c}\text { Pesticide } \\
\text { Weight (kg) }\end{array}$ & $\begin{array}{c}\text { Pesticide } \\
\text { Density }\left(\mathrm{g} \cdot \mathrm{cm}^{-3}\right)\end{array}$ \\
\hline 10 & 100 & 5 & 10 & 2 & 300 & 1 \\
\hline
\end{tabular}


Table A3. Coordinates of the vertices of each area.

\begin{tabular}{ccccccc}
\hline Area & P0 & P1 & P2 & P3 & P4 & P5 \\
\hline A & $(50,700)$ & $(50,867)$ & $(250,867)$ & $(250,700)$ & - & - \\
B & $(400,700)$ & $(477.46,922)$ & $(700,700)$ & - & - & - \\
C & $(515,1000)$ & $(515,1180)$ & $(700,1180)$ & $(700,1000)$ & - & - \\
D & $(760.8,1365)$ & $(815.1,1522.9)$ & $(1004,1458)$ & $(950,1300)$ & - & - \\
E & $(1188.3,1299.1)$ & $(1425.6,1411.7)$ & $(1440,1150)$ & - & - & - \\
F & $(915,1109)$ & $(938,1189)$ & $(1322.7,1079.8)$ & $(1300,1000)$ & - & - \\
G & $(1550,1150)$ & $(1648.6,1298)$ & $(1793.4,1298)$ & $(1833,1251)$ & $(1800,1150)$ & - \\
H & $(800,800)$ & $(899,948)$ & $(1099,948)$ & $(1050,800)$ & - & - \\
I & $(1121.5,778.5)$ & $(1333.6,990.6)$ & $(1412,912)$ & $(1200,700)$ & - & - \\
J & $(1370,755)$ & $(1584,977)$ & $(1670,755)$ & - & - \\
K & $(1817,650)$ & $(1817,900)$ & $(1950,900)$ & $(1950,650)$ & - \\
M & $(250,395)$ & $(250,506)$ & $(550,506)$ & $(550,395)$ & - \\
N & $(606.8,400)$ & $(753.4,617)$ & $(900,400)$ & - & - & - \\
O & $(1345,345)$ & $(945,428)$ & $(1345,428)$ & $(1345,345)$ & - \\
P & $(1800,300)$ & $(1800,433)$ & $(2050,433)$ & $(2050,300)$ & - \\
Q & $(429.5,239.2)$ & $(596.9,301.4)$ & $(759.6,185.1)$ & $(632.9,93.8)$ & - \\
R & $(900,150)$ & $(968.2,298)$ & $(1168.2,298)$ & $(1150,150)$ & - \\
Airport & $(1100,600)$ & & & - \\
\hline
\end{tabular}

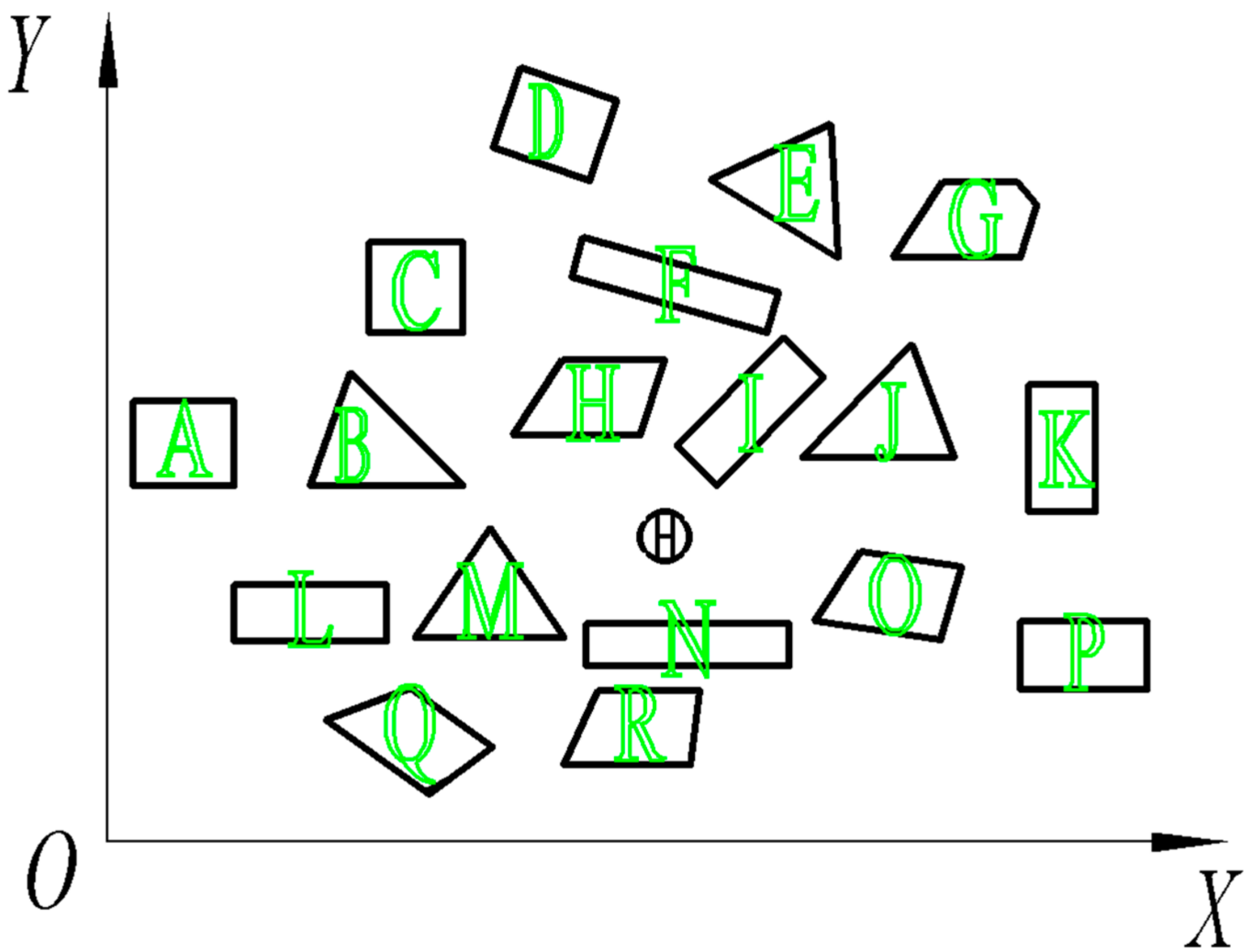

Figure A1. Multi-forest scheduling task map. 
Table A4. Coordinates of entry/exit points of eighteen forest areas (Unit: m).

\begin{tabular}{|c|c|c|c|c|c|c|}
\hline Area & $\begin{array}{l}\text { Abscissa Value } \\
\text { of Point } 1\end{array}$ & $\begin{array}{l}\text { Ordinate Value } \\
\text { of Point } 1\end{array}$ & $\begin{array}{c}\text { Abscissa Value } \\
\text { of Point } 2\end{array}$ & $\begin{array}{l}\text { Ordinate Value } \\
\text { of Point } 2\end{array}$ & $\begin{array}{l}\text { Abscissa Value } \\
\text { of Midpoint }\end{array}$ & $\begin{array}{c}\text { Ordinate Value } \\
\text { of Midpoint }\end{array}$ \\
\hline A & 45.00 & 705.00 & 255.00 & 865.00 & 150.00 & 785.00 \\
\hline B & 396.45 & 705.00 & 469.73 & 915.00 & 433.09 & 810.00 \\
\hline $\mathrm{C}$ & 510.00 & 1105.00 & 510.00 & 1175.00 & 510.00 & 1140.00 \\
\hline $\mathrm{D}$ & 757.74 & 1371.30 & 1008.32 & 1452.43 & 883.03 & 1411.87 \\
\hline $\mathrm{E}$ & 1183.45 & 1309.49 & 1436.72 & 1391.00 & 1310.09 & 1350.25 \\
\hline $\mathrm{F}$ & 911.76 & 1115.42 & 930.88 & 1182.76 & 921.32 & 1149.09 \\
\hline $\mathrm{G}$ & 1547.32 & 1155.00 & 1802.52 & 1295.00 & 1674.92 & 1225.00 \\
\hline $\mathrm{H}$ & 797.32 & 805.00 & 1102.91 & 945.00 & 950.12 & 875.00 \\
\hline I & 1192.93 & 700.00 & 1341.42 & 989.91 & 1267.18 & 844.96 \\
\hline $\mathrm{J}$ & 1371.93 & 750.00 & 1669.37 & 770.05 & 1520.65 & 760.03 \\
\hline $\mathrm{K}$ & 1822.00 & 905.00 & 1942.00 & 645.00 & 1882.00 & 775.00 \\
\hline $\mathrm{L}$ & 245.00 & 400.00 & 555.00 & 500.00 & 400.00 & 450.00 \\
\hline M & 598.07 & 405.00 & 773.56 & 605.00 & 685.82 & 505.00 \\
\hline $\mathrm{N}$ & 940.00 & 350.00 & 940.00 & 420.00 & 940.00 & 385.00 \\
\hline $\mathrm{O}$ & 1394.14 & 439.26 & 1688.26 & 535.77 & 1541.20 & 487.52 \\
\hline $\mathrm{P}$ & 1795.00 & 305.00 & 2055.00 & 425.00 & 1925.00 & 365.00 \\
\hline $\mathrm{Q}$ & 430.22 & 244.80 & 761.33 & 180.22 & 595.78 & 212.51 \\
\hline$\widehat{\mathrm{R}}$ & 896.80 & 155.00 & 1172.88 & 295.00 & 1034.84 & 225.00 \\
\hline Airport & 1100.00 & 600.00 & 1100.00 & 600.00 & 1100.00 & 600.00 \\
\hline
\end{tabular}

Table A5. Longitude and latitude coordinates of the five forest areas in the experiment.

\begin{tabular}{|c|c|c|c|c|c|}
\hline Area & P1 & P2 & P3 & $\mathbf{P 4}$ & P5 \\
\hline A & $\left(118^{\circ} 23^{\prime} 03^{\prime \prime}, 32^{\circ} 49^{\prime} 50^{\prime \prime}\right)$ & $\left(118^{\circ} 23^{\prime} 09^{\prime \prime}, 32^{\circ} 49^{\prime} 45^{\prime \prime}\right)$ & $\left(118^{\circ} 23^{\prime} 17^{\prime \prime}, 32^{\circ} 49^{\prime} 47^{\prime \prime}\right)$ & $\left(118^{\circ} 23^{\prime} 11^{\prime \prime}, 32^{\circ} 49^{\prime} 52^{\prime \prime}\right)$ & - \\
\hline $\mathrm{B}$ & $\left(118^{\circ} 23^{\prime} 13^{\prime \prime}, 32^{\circ} 49^{\prime} 53^{\prime \prime}\right)$ & $\left(118^{\circ} 23^{\prime} 19^{\prime \prime}, 32^{\circ} 49^{\prime} 46^{\prime \prime}\right)$ & $\left(118^{\circ} 23^{\prime} 29^{\prime \prime}, 32^{\circ} 49^{\prime} 48^{\prime \prime}\right)$ & $\left(118^{\circ} 23^{\prime} 25^{\prime \prime}, 32^{\circ} 49^{\prime} 53^{\prime \prime}\right)$ & - \\
\hline $\mathrm{C}$ & $\left(118^{\circ} 23^{\prime} 27^{\prime \prime}, 32^{\circ} 49^{\prime} 47^{\prime \prime}\right)$ & $\left(118^{\circ} 23^{\prime} 29^{\prime \prime}, 32^{\circ} 49^{\prime} 43^{\prime \prime}\right)$ & $\left(118^{\circ} 23^{\prime} 37^{\prime \prime}, 32^{\circ} 49^{\prime} 46^{\prime \prime}\right)$ & $\left(118^{\circ} 23^{\prime} 36^{\prime \prime}, 32^{\circ} 49^{\prime} 52^{\prime \prime}\right)$ & - \\
\hline $\mathrm{D}$ & $\left(118^{\circ} 23^{\prime} 37^{\prime \prime}, 32^{\circ} 49^{\prime} 51^{\prime \prime}\right)$ & $\left(118^{\circ} 23^{\prime} 39^{\prime \prime}, 32^{\circ} 49^{\prime} 48^{\prime \prime}\right)$ & $\left(118^{\circ} 23^{\prime} 45^{\prime \prime}, 32^{\circ} 49^{\prime} 50^{\prime \prime}\right)$ & $\left(118^{\circ} 23^{\prime} 43^{\prime \prime}, 32^{\circ} 49^{\prime} 53^{\prime \prime}\right)$ & - \\
\hline $\mathrm{E}$ & $\left(118^{\circ} 23^{\prime} 20^{\prime \prime}, 32^{\circ} 49^{\prime} 42^{\prime \prime}\right)$ & $\left(118^{\circ} 23^{\prime} 21^{\prime \prime}, 32^{\circ} 49^{\prime} 39^{\prime \prime}\right)$ & $\left(118^{\circ} 23^{\prime} 26^{\prime \prime}, 32^{\circ} 49^{\prime} 35^{\prime \prime}\right)$ & $\left(118^{\circ} 23^{\prime} 30^{\prime \prime}, 32^{\circ} 49^{\prime} 40^{\prime \prime}\right)$ & $\left(118^{\circ} 23^{\prime} 25^{\prime \prime}, 32^{\circ} 49^{\prime} 43^{\prime \prime}\right)$ \\
\hline
\end{tabular}

\section{References}

1. Wang, J.; Feng, L.; Palmer, P.I.; Liu, Y.; Fang, S.; Bösch, H.; O’Dell, C.W.; Tand, X.; Yang, D.; Liu, L.; et al. Publisher Correction: Large Chinese land carbon sink estimated from atmospheric carbon dioxide data. Nature 2020, 588, E19. [CrossRef]

2. Chen, C.; Park, T.; Wang, X.; Piao, S.; Xu, B.; Chaturvedi, R.K.; Fuchs, R.; Brovkin, V.; Ciais, P.; Fensholt, R.; et al. China and India lead in greening of the world through land-use management. Nat. Sustain. 2019, 2, 122-129. [CrossRef]

3. Zhou, Z.; Ming, R.; Zang, Y.; He, X.; Luo, X.; Lan, Y. Development status and countermeasures of agricultural aviation in China. Trans. Chin. Soc. Agric. Eng. 2017, 33, 1-13.

4. Fernandes Brilhante, A.; Lima, L.; Moreira de Ávila, M.; Medeiros-Sousa, A.R.; Ferreira de Souza, J.; Dos Santos, N.P.; Bicudo de Paula, M.; Godoy, R.E.; Basan Sábio, P.; de Oliveira Cardoso, C.; et al. Remarkable diversity, new records and Leishmania detection in the sand fly fauna of an area of high endemicity for cutaneous leishmaniasis in Acre state, Brazilian Amazonian Forest. Acta Trop. 2021, 223, 106103. [CrossRef] [PubMed]

5. Horton, D.R.; Miliczky, E.; Waters, T.D.; Burckhardt, D.; Halbert, S.E. Exotic Psyllids and Exotic Hosts: Accumulation of Nonnative Psylloidea in North America (Hemiptera). Ann. Entomol. Soc. Am. 2021, 114, 425-477. [CrossRef]

6. Carnegie, A.J.; Nahrung, H.F. Post-Border Forest Biosecurity in Australia: Response to Recent Exotic Detections, Current Surveillance and Ongoing Needs. Forests 2019, 10, 336. [CrossRef]

7. Martín-García, J.; Lukačevičová, A.; Flores-Pacheco, J.A.; Diez, J.J.; Dvořák, M. Evaluation of the Susceptibility of Several Czech Conifer Provenances to Fusarium circinatum. Forests 2018, 9, 72. [CrossRef]

8. Mehl, J.; Wingfield, M.J.; Roux, J.; Slippers, B. Invasive Everywhere? Phylogeographic Analysis of the Globally Distributed Tree Pathogen Lasiodiplodia theobromae. Forests 2017, 8, 145. [CrossRef]

9. Guo, C.; Ya, M.; Xu, Y.; Zheng, J. Comparison on discharge characteristics of conical and hyperbolic hoppers based on finite element method. Powder Technol. 2021, 394, 300-311. [CrossRef]

10. Dai, X.; Xu, Y.; Zheng, J.; Ma, L.; Song, H. Comparison of image-based methods for determining the inline mixing uniformity of pesticides in direct nozzle injection systems. Biosyst. Eng. 2020, 190, 157-175. [CrossRef]

11. Ru, Y.; Jin, L.; Jia, Z.; Bao, R.; Qian, X. Design and experiment on electrostatic spraying system for unmanned aerial vehicle. Trans. Chin. Soc. Agric. Eng. 2015, 31, 42-47. 
12. Tubby, K.; Forster, J. The potential role of aerial pesticide applications to control landscape-scale outbreaks of pests and diseases in British forestry with a focus on dothistroma needle blight. For. Int. J. For. Res. 2021, 94, 347-362. [CrossRef]

13. Schmidt, J.R.; Cheein, F.A. Assessment of power consumption of electric machinery in agricultural tasks for enhancing the route planning problem. Comput. Electron. Agric. 2019, 163, 104868. [CrossRef]

14. Lan, Y.B.; Chen, S.D. Current status and trends of plant protection UAV and its spraying technology in China. Int. J. Prec. Agric. Aviat. 2018, 1, 1-9. [CrossRef]

15. Hsu, A.J.; Pruckner, S.; Satterthwaite, E.V.; Weatherdon, L.V.; Hadley, K.; Nguyen, E.T.T. Challenges and Recommendations for Equitable Use of Aerial Tools for Mangrove Research. Front. Mar. Sci. 2021, 8, 277. [CrossRef]

16. Zhan, Y.; Chen, S.; Wang, G.; Fu, J.; Lan, Y. Biological control technology and application based on agricultural unmanned aerial vehicle (UAV) intelligent delivery of insect natural enemies (Trichogramma) carrier. Pest Manag. Sci. 2021, 77, 3259-3272. [CrossRef]

17. Cabreira, T.M.; Brisolara, L.B.; Ferreira, P.R.J. Survey on Coverage Path Planning with Unmanned Aerial Vehicles. Drones 2019, 3, 4. [CrossRef]

18. Causa, F.; Fasano, G.; Grassi, M. Multi-UAV Path Planning for Autonomous Missions in Mixed GNSS Coverage Scenarios. Sensors 2018, 18, 4188. [CrossRef] [PubMed]

19. Xu, B.; Chen, L.P.; Xu, M.; Tan, Y. Path planning algorithm for plant protection UAVs in multiple operation areas. Trans. Chin. Soc. Agric. Mach. 2017, 48, 75-81.

20. Fan, Y.; Shen, K.; Wang, D.; Wang, D.; Zhai, C.; Zhang, H. Optimal energy consumption path planning of UAV on mountain region based on simulated annealing algorithm. Trans. Chin. Soc. Agric. Mach. 2020, 51, 34-41.

21. Wang, Y.; Wang, W.; Xu, F.; Wang, J.; Chen, H. Path planning approach based on improved ant colony optimization for sprayer UAV. Trans. Chin. Soc. Agric. Mach. 2020, 51, 103-112.

22. Wilhelm, A.; Lefering, R. Helicopter Hoist Operations in Difficult Nonalpine Terrain. Air Med. J. 2021, 40, 242-250. [CrossRef] [PubMed]

23. Liu, Y.; Ru, Y.; Liu, B.; Chen, X. Algorithm for planning full coverage route for helicopter aerial spray. Trans. Chin. Soc. Agric. Eng. 2020, 36, 73-80.

24. Salcedo, R.; Zhu, H.; Zhang, Z.; Wei, Z.; Chen, L.; Ozkan, E.; Falchieri, D. Foliar deposition and coverage on young apple trees with PWM-controlled spray systems. Comput. Electron. Agric. 2020, 178, 105794. [CrossRef]

25. Wu, Y.; Qi, L.; Zhang, Y.; Elizabeth, M.; Li, S.; Cheng, Z.; Cheng, Y. Design and test of real-time monitoring system for UAV variable spray. Trans. Chin. Soc. Agric. Mach. 2020, 51, 91-99.

26. Popescu, D.; Stoican, F.; Ichim, L. Control and optimization of UAV trajectory for aerial coverage in photogrammetry applications. Adv. Electr. Comput. Eng. 2016, 16, 99-106. [CrossRef]

27. Torres, M.; Pelta, D.A.; Verdegay, J.L.; Torres, J.C. Coverage path planning with unmanned aerial vehicles for 3D terrain reconstruction. Expert Syst. Appl. 2016, 55, 441-451. [CrossRef]

28. Flood, M.M. The Traveling-Salesman Problem. Oper. Res. 1956, 4, 61-75. [CrossRef]

29. Mirjalili, S.; Gandomi, A.H.; Mirjalili, S.Z.; Saremi, S.; Faris, H.; Mirjalili, S.M. Salp swarm algorithm: A bio-inspired optimizer for engineering design problems. Adv. Eng. Softw. 2017, 114, 163-191. [CrossRef]

30. Ngatchou, P.; Zarei, A.; El-Sharkawi, A. Pareto Multi Objective Optimization. In Proceedings of the IEEE 13th International Conference on, Intelligent Systems Application to Power Systems, Arlington, VA, USA, 6-10 November 2005.

31. Wolpert, D.H.; Macready, W.G. No free lunch theorems for optimization. IEEE Trans. Evol. Comput. 1997, 1, 67-82. [CrossRef]

32. Abbattista, F.; Abbattista, N.; Caponetti, L. An evolutionary and cooperative agents model for optimization. In Proceedings of the 1995 IEEE International Conference on Evolutionary Computation, Perth, Australia, 29 November-1 December 1995.

33. Chaudhary, R.; Banati, H. Improving convergence in swarm algorithms by controlling range of random movement. Nat. Comput. 2021, 20, 513-560. [CrossRef]

34. Jayalakshmi, G.A.; Sathiamoorthy, S.; Rajaram, R. A Hybrid Genetic Algorithm-A New Approach to Solve Traveling Salesman Problem. Int. J. Comput. Eng. Sci. 2001, 2, 339-355. [CrossRef]

35. Can, A. GAACO: A GA + ACO Hybrid for Faster and Better Search Capability. In Proceedings of the 3rd International Workshop on Ant Algorithms, Brussels, Belgium, 12-14 September 2002.

36. Benhala, B.; Ahaitouf, A. GA and ACO in hybrid approach for Analog Circuit Performance Optimization. In Proceedings of the IEEE International Conference on Multimedia Computing and Systems, Marrakech, Morocco, 14-16 April 2014.

37. Grefenstette, J.J. Genetic Algorithms and Machine Learning. Mach. Learn. 1988, 3, 95-99. [CrossRef]

38. Kirkpatrick, S.; Gelatt, D.J.; Vecchi, M.P. Optimization by Simmulated Annealing. Science 1983, 220, 671-680. [CrossRef]

39. Zhou, K.; Jensen, A.L.; Sørensen, C.G.; Busato, P.; Bothtis, D.D. Agricultural operations planning in fields with multiple obstacle areas. Comput. Electron. Agric. 2014, 109, 12-22. [CrossRef]

40. Dorigo, M.; Maniezzo, V.; Colorni, A. Ant system: Optimization by a colony of cooperating agents. IEEE Trans. Syst. Man Cybern. Part B Cybern. 1996, 26, 29-41. [CrossRef] [PubMed]

41. Eberhart, R.; Kennedy, J. A new optimizer using particle swarm theory. In Proceedings of the IEEE 6th International Symposium on Micro Machine and Human Science, Nagoya, Japan, 4-6 October 1995; pp. 39-43.

42. Ferdush, J.; Mondol, G.; Prapti, A.P.; Begum, M.; Sheikh MN, A.; Galib, S.M. An enhanced image encryption technique combining genetic algorithm and particle swarm optimization with chaotic function. Int. J. Comput. Appl. 2021, 43, 960-967. [CrossRef] 
43. Rathod, S.; Ghosh, A.; Kulkarni, R. Fast and accurate autofocusing algorithm in digital holography based on particle swarm optimization. Optik 2021, 247, 167946. [CrossRef]

44. Soni, B.; Roy, S.; Warsi, S. Particle Swarm Optimization in Bioinformatics, Image Processing, and Computational Linguistics. Int. J. Swarm Intell. Res. 2021, 12, 25-44. [CrossRef] 